\title{
Sürdürülebilir Kalkınma Kapsamında Yeşil Lojistik: Avrupa Birliği ve Türkiye Örneği
}

Emrullah METE*

\author{
$\ddot{O} \mathbf{z}$
}

Lojistik ve ulaştırma altyapısındaki gelişmeler, ticaret hacmini artırma ve uluslararası rekabet gücü açısından hayati öneme sahiptir. Lojistik faaliyetlerinin artı̧̧ı ise sera gazı ve karbondioksit emisyonlarındaki yükselmeyle birlikte çevre üzerinde olumsuz etki yaratmaktadır. Lojistik faaliyetlerinin olumsuz etkisini azaltmak amacıyla ortaya çıkarılan yeşil lojistik ile çevresel, sosyal ve ekonomik hedefler arasında sürdürülebilir bir dengenin kurulması amaçlanmaktadır. Bu çalışmanın amacı lojistik faaliyetlerindeki gelişimin sera gazı ve karbondioksit emisyonu üzerindeki etkisinin araştırılmasıdır. Bu kapsamda, 2010 - 2018 döneminde Avrupa Birliği üyesi 26 ülke ve Türkiye'de gerçekleşen lojistik faaliyetlerin sera gazı ve karbondioksit emisyonları üzerindeki etkisi panel regresyon modeli ile analiz edilmiştir. Analiz sonuçlarına göre, ülkelerin lojistik faaliyetlerindeki gelişim ile sera gazı ve karbondioksit emisyonları arasında negatif ve anlamlı bir ilişkiye ulaşılmıştır. Aynı zamanda çalışma sonuçlarına göre yenilenebilir enerji kaynaklarının kullanım oranı ile sera gazı ve karbondioksit emisyonları arasında negatif ve anlamlı bir ilişki tespit edilmiştir.
\end{abstract}

Anahtar kelimeler: Yeşil Lojistik, Sürdürülebilir Kalkınma, Sera Gazı Emisyonu, Karbondioksit Emisyonu.

\section{Green Logistics Context of Sustainable Development: The Case of The European Union and Turkey}

\begin{abstract}
Developments in logistics and transportation infrastructure are of vital importance in terms of increasing trade volüme and international competitiveness. The increase in logistics activities, together with the increase in greehouse gas and carbon dioxide emissions, harms the environment. It is aimed to establish a sustainable balance between environmental, social and economic targets with green logistics activities. The aim of this study is to investigate the effect of the development in logistics activities on greenhouse gas and carbon dioxide emissions. In this context the effect of logistics activities that occur in 26 member states of the European Union and Turkey on greenhouse gas and carbon dioxide emissions in the 2010-2018 period analyzed by the panel regression model. According to the results of the analysis, a negative and significant relationship has been reached between the development in the logistics activities of the countries and greenhouse gas and carbon dioxide emissions. Besides, a negative and significant relationship has been found between the utilization rate of renewable energy sources and greenhouse gas and carbon dioxide emissions.
\end{abstract}

Keywords: Green Logistics, Sustainable Development, Greenhouse Gas Emission, Carbon Dioxide Emissions.

Geliş/Received: 04. 09. 2020

Kabul/Accepted: 02. 12. 2020

* Bu çalışma, insanlardan veri ve örnek toplamayı gerektiren, anket, inceleme, alan çalışması ve deney içeren araştırmalar 'kapsamına girmediğinden etik kurul onay belgesi gerektirmemektedir.

\footnotetext{
* Dr. Öğr. Üyesi, Giresun Üniversitesi, Görele Uygulamalı Bilimler Yüksekokulu, Lojistik Yönetimi Bölümü, emrullah.mete@ giresun.edu.tr, orcid.org/0000-0003-2240-9248

(Makale türü: Araştırma makalesi)
} 


\section{Emrullah METE}

Sürdürülebilir Kalkınma Kapsamında Yeșil Lojistik: Avrupa Birliği ve Türkiye Örneği

\section{Giriş}

Lojistik, müşterilerin ihtiyaçlarını karşılamak üzere her türlü ürün, servis hizmeti ve bilgi akışının, başlangıç noktasından son noktaya kadar hareketinin etkili ve verimli bir biçimde planlanması, uygulanması, taşınması, depolanması ve kontrol altında tutulması işlemi şeklinde tanımlanabileceği gibi doğru ürünün doğru yerde, doğru zamanda, doğru miktarda, doğru şekilde, doğru kalitede ve rekabetçi bir fiyatla sağlanması şeklinde de ifade edilebilmektedir (Takım, 2015). Lojistik altyapısının gelişmesi, üretim ve dış ticaret faaliyetlerini doğrudan artırdığından ve aynı zamanda üretim maliyetlerine de düşürücü etki yaptığından dolayı ülkelerin uluslararası rekabet güçlerini artırmaktadır. Ülke ekonomileri için hayati önem taşıyan lojistik hizmetlerinde meydana gelebilecek bir olumsuzluk hem mali hem de zaman açısından ticaret hacminde önemli aksaklıklara neden olmaktadır. Dünya Bankası tarafından yapılan çalışmada, lojistik hizmetlerde yaşanabilecek bir günlük gecikmenin ticaret hacmini $\% 1$ oranında azalttığı, bu oranın zamanlamanın oldukça önemli olduğu tarım ürünlerinde ise ihracatı $\% 7$ oranında azalttığı sonuçlarına ulaşılmıştır (Onuncu Kalkınma Planı Özel İhtisas Komisyonu Raporu, 2014).

Güçlü bir altyapı ile rekabet gücü kazandırabilecek olan lojistik faaliyetler ancak yüksek maliyetli yatırımlarla mümkün olabilmektedir. Özellikle lojistik faaliyetlerin en önemli halkası konumunda olan ulaştırma faaliyetlerine yönelik alt yapı yatırımları maliyetlerin büyük kısmını oluşturmaktadır. Bu sebeple ülkeler lojistik faaliyetlerinin artırılması ve altyapıların geliştirilmesi konusunda önemli bütçeler ayırmak zorundadır.

Bir yanda lojistik altyapının geliştirilmesi ve bu sayede ülke ekonomisine katma değer yaratma hedefi yer alırken, diğer yanda da dünya ülkelerinin tamamını ilgilendiren büyüme, gelişme ve kalkınma konusundaki sürdürülebilirlik hedefi yer almaktadır. Ülke ekonomisine katma değer yaratan faaliyetlerin giderek artması aynı zamanda doğal çevre ve doğal kaynakların tahrip edilmesini de beraberinde getirmektedir. Doğal kaynaklar ve çevrenin tahribatı uzun dönemli büyümeyi artırıcı faaliyetlere imkan tanımayacağından dolayı çevreye ve doğal kaynaklara duyarlı bir büyüme kalkınma modelinin oluşturulması zorunlu hale gelmiştir. Sürdürülebilir kalkınma olarak ifade edilen bu model, ekonomik faaliyetler ile doğa arasında denge kurarak yani kaynaklanı asgari düzeyde kullanarak bugünün ve geleceğin yaşamını ve kalkınmasını garanti eden bir kalkınma modelidir. Daha açık bir ifade ile ekonomik faaliyetleri ve dolayısıyla büyümeyi, çevreyi ve doğal kaynakları gelecek nesillere de miras brrakabilecek düzeyde kullanarak sağlayan, çevre ve doğal kaynakların korunmasını yüksek büyüme oranlarına tercih eden bir modeldir. Bu kapsamda, özellikle çevre ve hava kirliliğiyle alakalı uluslararası platformlarda birçok çalışma ve konferanslar düzenlenmekle birlikte ilk etkili girişim Kyoto Protokolü olmuştur. Sanayileşmiş ülkelere sera gazı emisyonlarını kısmak üzere hedefler belirleyen Kyoto Protokolü 1997 yılında Japonya'da imzalanmıştır. 2012 yılında, Avrupa 
Birliği'nin 2020 stratejisi çerçevesinde 31 Aralık 2020 tarihine kadar geçerli olması öngörülen 7. Çevre Eylem Planı kabul edilmiştir. Bu planda Avrupa Birliği, 2020 yılına kadar akıllı, sürdürülebilir, kapsayıcı, düşük karbonlu ve kaynak açısından verimli bir ekonomi amaçlayan bir dizi politika ve eylem belirlemiştir. Çevre ve iklim politikaları için gerekli yatırımın sağlanması, yeşil, rekabetçi düşük karbon ekonomisine geçişin sağlanması, Birliğin uluslararası çevre ve iklim sorunları konusundaki etkinliğinin güçlendirilmesi gibi öncelikli hedeflerin yanı sıra çevresel hedeflerin diğer birlik politikaları ve faaliyetlerine entegre edilmesi de Eylem Planı'na dahil edilmiştir (Dışişleri Bakanlığı AB Başkanlığı, 2020). İklim değişikliğiyle mücadele enerji politikasının ayrılmaz bir parçası haline gelmiş ve kaynak verimliliği, iklim değişikliği ve enerji verimliliği kaygılarını lojistik, ulaşım ve inşaat gibi diğer kilit sektörlere entegre etme konusunda ilerleme kaydedilmiştir (Dereli ve Aytaç, 2019). Yine 2012 yılında Rio'da düzenlenen Birleşmiş Milletler Sürdürülebilir Kalkınma Konferansında çevrenin korunması çerçevesinde bir ekonomi modeli tanımlanmış ve "çevresel riskleri ve ekolojik kıtlığı azaltan, buna karşılık sosyal eşitliği ve refahı artıran" bu modele yeşil ekonomi adı verilmiştir. Yeşil ekonomiyle birlikte birçok kavram yeşil başlığı altında literatürde kendine yer bulmuş olup, bunlardan biri de yeşil lojistik olmuştur. Lojistik hizmetler içerisinde ise taşımacılık ve özellikle karayolu taşımacılığı önemli bir paya sahiptir. Ancak karayolu taşımacılığı büyük oranda fosil yakıtlarla çalışan taşıma araçları ile yapıldığından, sera gazı emisyonunun artmasına sebep olmakta, çevre üzerinde önemli sorunlara neden olmaktadır. Bu nedenle tüm ekonomik faaliyetlerin gerekliliği olan lojistiğin, emisyon sorununu ortaya çıkararak başta küresel ısınma ve iklim değişikliği olmak üzere çevre ve insan sağlığını tehdit eden sorunlara yol açması, lojistik faaliyetlerin çevre ile uyumlu olarak organize edilmesini gerekli kılmıştır. Bu kapsamda, çevre ile uyumlu hale getirilen lojistik, doğal kaynakların korunması, yenilenebilir kaynakların kullanılması, sera gazı emisyonlarının ve atıkların en aza indirgenmesini hedef olarak barındıran yeşil lojistik adını almıştır (Yılmaz ve Keser, 2018).

Yeşil lojistik kapsamındaki lojistik faaliyetler ile sera gazı karbondioksit emisyonları arasındaki ilişkinin ele alındığı bu çalışmada, emisyonu artırıcı etkisinin fazla olması nedeniyle lojistik performans endeksini belirleyen bileşenlerden ticaret ve taşımacılık ile ilgili alt yapı kalitesini gösteren endeks ayrıca değerlendirilmiştir. Avrupa Birliği’nin 2020 stratejisinin etkilerinin değerlendirilmesi açısından AB 26 ile batısında Avrupa ülkeleri, doğusunda ise Asya ülkeleri bulunan, yaklaşık olarak dünya ticaretinin \%70'inin gerçekleştiği bir alanda aktarma merkezi konumunda yer alan Türkiye, yeşil lojistik kavramı çerçevesinde değerlendirilmiştir. 2010 - 2018 arası dönemin ele alındığ bölümden oluşmaktadır. Giriş bölümünden sonra birinci bölümde çalışma konusuna ilişkin literatür yer almaktadır. İkinci bölümde analizde kullanılan veriler ile analiz yöntemine ilişkin 


\section{Emrullah METE}

Sürdürülebilir Kalkınma Kapsamında Yeșil Lojistik: Avrupa Birliği ve Türkiye Örneği

bilgiler verilmiştir. Üçüncü bölümde analiz sonuçları değerlendirilmiş olup, dördüncü ve son bölüm ise sonuç ve değerlendirme kısmından oluşmaktadır.

\section{Literatür}

Lojistik sektörü ve yeşil lojistik, küresel ticaretle birlikte oldukça önemli bir konumda olması nedeniyle ekonomi literatüründe çok sayıda çalışmaya konu olmuştur. Bu kısımda, çalışmanın konusu itibariyle genel anlamda lojistik ile ilgili çalışmalardan ziyade lojistiğin çevre üzerindeki etkisini azaltma amacında olan yeşil lojistik ile ilgili çalışmalar ele alınmıştır.

Bu kapsamda, Lai ve Wong (2012) yeşil lojistiğin çevresel ve operasyonel performans üzerindeki etkilerini Çin'deki imalat sanayii ihracatçı firmaları üzerinden değerlendirmişlerdir. Anket yöntemiyle elde edilen verilerle yapılan faktör analizi sonuçlarına göre yeşil lojistik yönetiminin, karbondioksit emisyonu ve atığı azaltma ile ihracatçı firmaların rekabet gücünü artırma konusundaki çevresel ve operasyonel performansları arasında pozitif bir korelasyon olduğu saptanmıştır.

Cui ve Li (2015) ulaşım sektöründeki karbon verimliliğini etkileyen faktörleri gelişmiş ülke statüsündeki 15 ülkeyi ele alarak 2003-2010 dönemi için incelemişlerdir. Tobit regresyon modelinin kullanıldığı çalışmada, ulaşım ve karbon teknolojisine yönelik ar-ge harcamalarının karbon verimliliği ile pozitif yönlü ilişki içinde olduğu ve kamunun düşük karbonlu taşımacılığa yönelik uygulamalarının ulaşım sektörü karbon verimliliği üzerin olumlu etki yarattığ sonuçlarına ulaşılmıştır.

Nakamichi, Hanaoka ve Kawahara (2016), Tayland'daki nakliye ve üretim süreçleri de dahil olmak üzere her bir gönderinin toplam karbon emisyonuna etkisini araştırmıştır. Bulgular, üretim tesislerinin tüketicilere yakın yerlerde olmasının karbondioksit emisyonlarını önemli ölçüde azaltabileceğini göstermektedir.

Mariano, Gobbo, Camioto ve Rebelatto (2017) ulaştırma sektöründe karbondioksit emisyonu ile lojistik performans endeksi arasındaki ilişkiyi 104 ülke için inceledikleri çalışmada veri zarflama analizini kullanmışlardır. 2007, 2010 ve 2012 yıllarının analiz edildiği çalışma sonuçlarına göre gelişmiş ülkelerin düşük karbondioksit emisyonuyla birlikte iyi lojistik performansına sahip olduğu ayrıca, teknolojik gelişmelerden dolayı 2007-2010 döneminde 20102012 dönemine nazaran ülkelerin düşük karbondioksit emisyonlarını iyi lojistik performansına dönüştürme noktasında daha fazla gelişme kaydettiği tespit edilmiştir.

Zaman ve Shamsuddin (2017), 2007 - 2014 dönemi için 27 Avrupa Birliği ülkesi çerçevesinde lojistik performans endeksinin enerji, çevre ve sağlı harcamaları gibi ulusal ekonomik göstergeler üzerindeki etkisini inceledikleri çalışmalarında panel Genelleştirilmiş Momentler Metodu (GMM) kullanmışlardır. Analiz sonuçlarına göre lojistik performans endeksini oluşturan unsurlardan biri olan zamanlama, Gayri Safi Yurtiçi Hasıla (GSYİH), kişi 
başı gelir, sağlık harcamaları, kişi başı enerji kullanımını önemli ölçüde artırmakta; alt yapı unsuru ise yenilenebilir enerji kaynakları kullanımını artırırken, karbon emisyonunu azaltmaktadır. Bununla birlikte takip ve izleme ile sevkiyat unsurlarının fosil yakıt kullanımını artırdığına ilişsin bulgular da mevcuttur.

Aldakhil, Nassani, Awan, Abro ve Zaman (2018), BRICS (Brezilya, Rusya, Hindistan, Çin ve Güney Afrika Cumhuriyeti) ülkeleri özelinde 1995-2015 dönemi için sosyo-ekonomik ve çevresel faktörler ile lojistik performans endeksleri arasındaki dinamik bağlantıları incelemişlerdir. Panel eş bütünleşme analizinin uygulandığı çalışmanın sonuçlarına göre, karbon emisyonları, kişi başına gelir ve suç oranları farklı lojistik performans endeksleriyle önemli ölçüde ilişkiliyken, fosil emisyonları ve ticaret serbestleştirme politikaları lojistik performans endeksleriyle desteklenmemektedir. Nedensellik analizi ise, kişi başına gelir ile "lojistik hizmetlerin kalitesi" ile sosyal faktör ve "rekabetçi fiyatlı sevkiyat" arasındaki çift yönlü ilişkiyi doğrulamıştır.

Yu, Golpira ve Khan, (2018), yeşil lojistik, enerji talebi, yenilenebilir enerji tüketimleri, çevresel performans ve sürdürülebilir ekonomik kalkınma arasındaki ilişkiyi, 2008-2017 dönemi boyunca dünya genelinde on dokuz gelişmiş ekonomiden oluşan bir panelde incelemişlerdir. Sonuçlar, yeşil lojistik göstergelerinin yeşil enerji kaynakları, doğrudan yabancı yatırım girişleri ve ticaret açıklığı ile güçlü bir pozitif korelasyona sahip olduğunu ortaya koymaktadır. Öte yandan, sera gazı emisyonları ve karbon emisyonlarının yeşil lojistik ile negatif korelasyonu vardır. Bununla birlikte çalışmada yenilenebilir enerjinin, çevresel ve ekonomik sürdürülebilirliği de destekleyen yeşil lojistik ve tedarik zinciri operasyonlarının itici faktörü olduğu sonucuna ulaşılmıştır.

Wang, Dong, Peng, Khan ve Tarasov (2018) yeşil lojistik ile uluslararası ticaret arasındaki ilişkiyi gelişmiş ve gelişmekte olan 113 ülke açısından değerlendirmişlerdir. 20072014 dönemi için genişletilmiş çekim modelinin kullanıldığı çalışmada ihracatçı ülkelerin yeşil lojistik performansı, ihracat olasılığını ve hacmini olumlu etkilemektedir. Ayrıca, gelişmekte olan-gelişmekte olan ülkeler, gelişmiş-gelişmiş ülkeler ve gelişmiş-gelişmekte olan ülkeler arasındaki ticarette, ithalatçı ülkelerin yeşil lojistik performansı ihracatçı ülkelerin ihracat hacmini olumsuz etkilemektedir. Diğer yandan gelişmekte olan-gelişmiş ülkeler arasındaki ticaret açısından, ithalatçı ülkelerin yeşil lojistik performansının ihracat olasılığını olumsuz, ihracat hacmini olumlu etkilediği görülmektedir. Son olarak analiz sonuçları ihracat yapan ülkeler açısından lojistik sektöründeki karbondioksit emisyonunu azaltmanın ve karbondioksit verimliliğini artırmanın ihracat hacmini artırabileceğini göstermektedir.

Khan (2019), ekonomik, çevresel ve sosyal faktörler ile yeşil lojistik endeksi arasındaki ilişkiyi Asya'nın yükselen ekonomilerini ele alarak değerlendirmiştir. Çalışmanın bulgularına 


\section{Emrullah METE}

Sürdürülebilir Kalkınma Kapsamında Yeșil Lojistik: Avrupa Birliği ve Türkiye Örneği

göre lojistik operasyonlar kişi başına gelir, ticaret açıklığı ve sektör katma değeri açısından ekonomik büyümeye katkı sağlamakta; karbon emisyonları, sera gazı emisyonları, fosil yakıt ve azot emisyonları nedeniyle ise çevresel sürdürülebilirliğe zarar vermektedir. Üstelik çalışmada lojistik operasyonların çocuklarda kalp hastalı̆̆ı, inme, akciğer kanseri ve akut alt solunum yolu enfeksiyonları gibi hastalıklara yol açan kirliliğin bir nedeni olduğu vurgulanmakta, söz konusu sosyal ve çevresel sorunların lojistik operasyonda yenilenebilir enerji ve yeşil uygulamaların benimsenmesi ile azaltılabileceği ileri sürülmektedir.

Khan, Zhang ve Nathaniel (2020) yeşil lojistik operasyonları, ulusal ekonomik ve çevresel göstergeler arasındaki ilişkiyi 2007-2018 dönemi için lojistik performans sıralamasındaki 42 ülke açısından değerlendirmişlerdir. Çalışmanın bulgularına göre yeşil lojistik faaliyetleri, doğrudan yabancı yatırım girişleri, yenilenebilir enerji tüketimi ve enerji talebi ile pozitif ve istatistiksel olarak anlamlı bir ilişkiye sahiptir. Ayrıca $\mathrm{CO}_{2}$ emisyonları ile yeşil lojistik arasında önemli bir negatif korelasyonun tespit edildiği çalışmanın bulgularına göre doğrudan yabancı yatırımlar ve yenilenebilir enerji, yeşil lojistik faaliyetlerinin itici gücü olup, çevresel sürdürülebilirliği de teşvik etmektedir.

Öncü ve Özdemir (2020) ekonomik büyüme ile ulaştırma altyapı kalitesinin karbondioksit emisyonu üzerindeki etkisini 2007-2017 dönemi için incelemişlerdir. Panel veri analizinin kullanıldığı ve 33 ülkenin ele alındığı çalışmada ulaştırma altyapı kalitesindeki artışın karbondioksit emisyonu üzerinde azaltıcı etki gösterdiği sonucuna ulaşılmıştır.

Literatür çerçevesinde değerlendirildiğinde sürdürülebilirlik konusu yeşil lojistik özelinde de son yıllarda ön planda yer alan konulardan biri olmuştur. Ekonomik gelişmişlik düzeylerine göre gruplandırılarak ve/veya bireysel olarak ülkelerin ele alındığı çalışmalarda ulaştırma ve lojistik faaliyetlerinin çevre ve hava kirliliği üzerindeki etkisi incelenmiştir. Bu çalışmada da literatüre katkı yapmak amacıyla Türkiye ile AB26 ülkeleri incelenmiştir. 2010 yılında açıklanan Avrupa 2020 stratejisiyle belirlenen sera gazı emisyonunu azaltma hedefi dikkate alınarak hem toplam sera gazı emisyonu hem de karbondioksit emisyonu üzerinde lojistik faaliyetlerinin etkisi değerlendirilmiştir. Lojistik faaliyetler de toplam lojistik performans endeksi ile ticaret ve ulaşımla ilgili altyapı kalitesi endeksi kapsamında ayrı ayrı değerlendirilmiştir.

\section{Veri Seti ve Yöntem}

AB26 ve Türkiye'de gerçekleşen lojistik faaliyetlerin sera gazı ve $\mathrm{CO}_{2}$ emisyonları üzerindeki etkisinin ele alındığı bu çalışmada 2010-2018 arası dönem değerlendirilmiştir. Panel veri analizinin kullanıldığı çalışmada 4 adet model kurulmuştur;

$$
\begin{aligned}
& \mathrm{LGHG}_{i t}=\alpha_{\mathrm{i}}+\beta_{1} \mathrm{LLPI}_{i \mathrm{it}}+\beta_{2} \mathrm{LGDPPC}_{\mathrm{it}}+\beta_{3} \mathrm{LRNC}_{\mathrm{it}}+\varepsilon_{\mathrm{it}} \\
& \mathrm{LGHG}_{\mathrm{it}}=\alpha_{\mathrm{i}}+\beta_{1} \mathrm{LLPI}_{\mathrm{it}}+\beta_{2} \mathrm{LGDPPC}_{\mathrm{it}}+\beta_{3} \mathrm{LRNC}_{\mathrm{it}}+\varepsilon_{\mathrm{it}} \\
& \mathrm{LCO}_{\mathrm{it}}=\alpha_{\mathrm{i}}+\beta_{1} \mathrm{LLPI}_{\mathrm{it}}+\beta_{2} \mathrm{LGDPPC}_{\mathrm{it}}+\beta_{3} \mathrm{LRNC}_{\mathrm{it}}+\varepsilon_{\mathrm{it}}
\end{aligned}
$$




$$
\mathrm{LCO}_{\mathrm{it}}=\alpha_{\mathrm{i}}+\beta_{1} \mathrm{LLPI}_{\mathrm{it}}+\beta_{2} \mathrm{LGDPPC}_{\mathrm{it}}+\beta_{3} \mathrm{LRNC}_{\mathrm{it}}+\varepsilon_{\mathrm{it}}
$$

Modellerde kullanılan değişkenlerden LGHG sera gazı emisyonunu (bin ton), LCO karbondioksit emisyonunu (bin ton), LLPI1 toplam lojistik performans indeksini, LLPI2 ticaret ve ulaşımla ilgili altyapı kalitesine ilişkin lojistik performans endeksini, LGDPPC kişi başı geliri (2010 sabit US\$), LRNC ise yenilenebilir enerji kaynakları kullanım oranını (\%) ifade etmektedir. Ayrıca, modellerde yer alan $\mathrm{t}$ zamanı, i birimleri, $\alpha$ sabit terimi, $\beta$ eğim parametresini, $\varepsilon$ ise hata terimini ifade etmektedir.

Analizde bağımlı değişken olarak sera gazı ve karbondioksit emisyonlarının ayrı ayrı ele alınması, toplam sera gazı emisyonu içerisindeki en büyük payın karbondioksit emisyonuna ait olmasından kaynaklanmıştır. Toplam lojistik performans endeksinin yanında ticaret ve ulaşımla ilgili alt yapı yatırımlarının kalitesine ilişkin endeksin de değişken olarak ele alınmasının nedeni ise emisyon salınımını artırıcı yönde en fazla etkiye sahip olduğu düşünülen faaliyet olmasıdır. Dolayısıyla her bir bağımlı değişken için iki farklı model kurulmuştur. Son olarak, ülkelere ait lojistik performans endeksleri Dünya Bankası tarafından 2007 y1lı itibariyle hesaplanmaya başlanmış ve 2010 yılı ve sonrasında ise iki yılda bir olarak yayımlanmaktadır. Dolayısıyla analizde kullanılan zaman serisi 2010 yılı itibariyle ele alınmıştır.

Değişkenlere ilişkin LGHG, LCO, LRNC verileri Avrupa Birliği resmi istatistik portalından (Eurostat), LLPI1, LLPI2 ve LGDPPC verileri ise Dünya Bankası veri tabanından elde edilmiştir. Tüm değişkenlere ilişkin verilerin logaritmaları alınarak analiz yapılmıştır.

Panel veri analizinin kullanıldığı modelde, klasik model, sabit etkiler modeli ve tesadüfi etkiler modellerinden hangisinin uygun olacağı noktasında F, LM, LR, Score testleri ve Wooldridge'in testi kullanılabilmektedir. Bu testlerin bir kısmı sabit, bir kısmı ise tesadüfi etkiler tahmincileri üzerinden yapılmaktadır. Birim etkinin olmadığını ifade eden $\mathrm{H}_{0}$ hipotezinin $\left(\mathrm{H}_{0}\right.$ : $\mu_{\mathrm{i}}=0$ ) reddedilmesi klasik modelin geçerli olmadığını göstermektedir (Tatoğlu, 2013). Sabit etkiler ve tesadüfi etkiler tahmincileri arasında seçim yapmak ve hangi modelin uygun olduğuna karar verebilmek için Hausman, Wald, t ve F testleri kullanılmaktadır. Sabit ve tesadüfi etkiler arasındaki en önemli farklardan birisi, birim etkilerin bağımsız değişkenlerle korelasyonlu olup olmadığı noktasıdır. Korelasyon olması durumunda sabit etkiler modeli, korelasyon olmaması durumunda ise tesadüfi etkiler modeli geçerli olmaktadır. Uygun tahmincinin belirlenmesinden sonra, heteroskedasite, otokorelasyon ve birimlerarası korelasyon gibi temel varsayımlardan sapmalar test edilmektedir. Sabit etkiler modelinde heteroskedasite değiştirilmiş Wald testi ile; otokorelasyon Baltagi-Wu'nun yerel en iyi değişmez testi ve Durbin-Watson testi ile; birimler arası korelasyon ise Breusch-Pagan (1980) Lagrange çarpanı testi, Pesaran (2004) CD testi ve Friedman'ın testi ile sinanabilmekte iken tesadüfi etkiler modelinde heteroskedasite BreuschPagan Lagrange çarpanı testi Levene, Brown ve Forsthe testi ile; otokorelasyon Baltagi-Wu'nun 


\section{Emrullah METE}

Sürdürülebilir Kalkınma Kapsamında Yeșil Lojistik: Avrupa Birliği ve Türkiye Örneği

yerel en iyi değişmez testi ve Durbin-Watson testi, Lagrange çarpanı testi, düzeltilmiş lagrange çarpanı testi ile; birimler arası korelasyon ise Pesaran'ın testi, Friedman'ın testi ve Frees'in testi ile sinanabilmektedir. Son olarak, heteroskedasite, otokorelasyon ve birimler aras korelasyondan en az birinin olması durumunda varyanslar ve dolayısıyla standart hatalar, $\mathrm{t}$ ve $\mathrm{F}$ istatistikleri, $\mathrm{R}^{2}$ ve güven aralıklarının geçerliliği etkilenmektedir. Böyle bir durumda ya parametre tahminlerine dokunmadan dirençli standart hatalar elde edilmeli ya da uygun yöntemlerle tahminler yapılmalıdır (Tatoğlu, 2013).

\section{Bulgular}

Lojistik faaliyetlerin sera gazı ve karbondioksit emisyonlarına etkisinin araştırıldığı bu çalışmada 4 farklı model kurulmuş ve her bir model için panel regresyon analiziyle sonuçlar değerlendirilmiştir. Her bir model için yapılan F testi ve Breusch-Pagan LM testi sonuçlarına göre klasik modelin uygun olmadı̆̆ı; Hausman testi sonuçlarına göre ise birim etkilerin bağımsız değişkenlerle korelasyonlu olduğu sonuçlarına ulaşılmış olup, modellerde sabit etkiler tahmincisinin kullanılmasının uygun olduğuna karar verilmiştir.

Her bir modelde sabit etkiler tahmincisinin uygun olduğu tespit edildikten sonra heteroskedasite, otokorelasyon ve birimler arası korelasyon durumları sınanmıştır. Modellerde heteroskedasitenin varlığı değiştirilmiş Wald testi ile sınanmış, $\mathrm{H}_{0}$ hipotezi reddedilerek heteroskedasitenin var olduğu tespit edilmiştir. Otokorelasyonun varlığı Durbin Watson ve Baltagi Wu'nun yerel en iyi değişmezlik testi ile sınanmış, test değerleri 2'den küçük olduğu için sabit etkiler modelinde otokorelasyon olduğu kabul edilmiştir. Birimler arası korelasyon ise Pesaran'ın testi ile sınanmış ve olasılık değeri $\mathrm{H}_{0}$ hipotezinin reddedilmesini gerektirmiştir. Tüm modellerde heteroskedasite, otokorelasyon ve birimler aras1 korelasyonun mevcut olmas1 sebebiyle dirençli standart hatalar elde edilmesi gereği ortaya çıkmış ve bunun için Driscoll ve Kraay (1998) tarafından geliştirilen tahminci uygulanmıştır. Modellere ilişkin panel regresyon analizi sonuçları bağımlı değişkenin sera gazı emisyonu (LGHG) olduğu modeller için Tablo 1'de, bağımlı değişkenin karbondioksit emisyonu (LCO) olduğu modeller için Tablo 2'de belirtilmiştir.

Tablo 1'de yer alan değerler incelendiğinde, bağımlı değişkenin sera gazı emisyonu (LGHG) olduğu (1) nolu model sonuçlarına göre, toplam lojistik performans endeksindeki \%1'lik bir artış sera gazı emisyonunda \%0.28'lik bir azalmaya sebep olmaktadır. Kişi başına hasıladaki $\% 1$ 'lik bir artış ise sera gazı emisyonunu \%0.09 oranında artırmaktadır. Yine (1) nolu model sonuçlarına göre yenilenebilir enerji kaynakları kullanımındaki \%1'lik bir artış sera gazı emisyonunda \%0.18'lik bir azalma meydana getirmektedir. Bağımlı değişkenin sera gazı emisyonu (LGHG) olduğu ancak (1) nolu modelden farklı olarak ticaret ve ulaşım altyapısının kalitesini ifade eden (LLPI2) bağımsız değişkeninin kullanıldığı (2) nolu model sonuçlarına göre, 
ticaret ve ulaşım altyapısının kalitesindeki \%1'lik bir artış sera gazı emisyonunda \%0.19 oranında bir azalmaya; kişi başına hasıladaki \%1'lik bir artış sera gazı emisyonunda \%0.11'lik bir artışa; yenilenebilir enerji kaynaklarının kullanım oranındaki \%1'lik bir artış ise sera gazı emisyonunda $\% 0.18$ 'lik azalmaya sebebiyet vermektedir.

Tablo 1: Lojistik Faaliyetlerin Sera Gazı Emisyonları Üzerine Etkisi (Bağımlı Değişken: LGHG)

\begin{tabular}{|c|c|c|}
\hline Değişkenler - Modeller & (1) & (2) \\
\hline \multirow[t]{2}{*}{ LLPI1 } & -0.281 & \\
\hline & $(0.015)^{* *}$ & \\
\hline \multirow[t]{2}{*}{ LLPI2 } & & -0.189 \\
\hline & & $(0.021)^{* * *}$ \\
\hline \multirow[t]{2}{*}{ LGDPPC } & 0.089 & 0.106 \\
\hline & $(0.009)^{*}$ & $(0.042)^{* * *}$ \\
\hline \multirow[t]{2}{*}{ LRNC } & -0.180 & -0.183 \\
\hline & $(0.010)^{* * *}$ & $(0.008)^{*}$ \\
\hline \multirow[t]{2}{*}{ Sabit Parametre } & 11.233 & 10.945 \\
\hline & $(0.000)^{*}$ & $(0.000)^{*}$ \\
\hline Gözlem Say1s1 & 243 & 243 \\
\hline Birim Sayısı & 27 & 27 \\
\hline $\mathrm{R}^{2}$ & 0,33 & 0.32 \\
\hline \multirow[t]{2}{*}{$\mathrm{F}$ testi $\left(\mathrm{H}_{0}: \mu_{\mathrm{i}} \neq 0\right)$} & 3863.77 & 3851.82 \\
\hline & $(0.000)$ & $(0.000)$ \\
\hline $\mathrm{F}$ testi $\left(\mathrm{H}_{0}: \beta_{\mathrm{i}}=0\right)$ & 34.63 & 34.08 \\
\hline \multirow[t]{2}{*}{ Breusch-Pagan LM (Pr>Chi2) } & 485.09 & 464.66 \\
\hline & $(0.000)$ & $(0.000)$ \\
\hline \multirow[t]{2}{*}{ Hausman $(\operatorname{Pr}>C h i 2)$} & 37.89 & 40.39 \\
\hline & $(0.000)$ & $(0.000)$ \\
\hline DW & 0.727 & 0.735 \\
\hline Baltagi-Wu & 1.131 & 1.145 \\
\hline \multirow[t]{2}{*}{ Pesaran testi } & 11.934 & 11.941 \\
\hline & $(0.000)$ & $(0.000)$ \\
\hline \multirow[t]{2}{*}{ Değiştirilmiş Wald testi } & 834.51 & 1248.07 \\
\hline & $(0.000)$ & $(0.000)$ \\
\hline
\end{tabular}

*,** sirasılyla $\% 1$ ve $\% 5$ düzeyinde anlamlılık seviyelerini göstermektedir. 


\section{Emrullah METE}

Sürdürülebilir Kalkınma Kapsamında Yeșil Lojistik: Avrupa Birliği ve Türkiye Örneği

Tablo 2'de yer alan değerler incelendiğinde, bağımlı değişkenin karbondioksit emisyonu (LCO) olduğu (3) nolu model sonuçlarına göre, toplam lojistik performans endeksindeki \%1'lik bir artış karbondioksit emisyonunda \%0.36'lık bir azalmaya sebep olmaktadır. Kişi başına hasıladaki \%1'lik bir artış ise karbondioksit emisyonunu \%0.08 oranında artırmaktadır. Yine (3) nolu model sonuçlarına göre yenilenebilir enerji kaynakları kullanımındaki \%1'lik bir artış karbondioksit emisyonunda \%0.22’lik bir azalma meydana getirmektedir. Bağımlı değişkenin karbondioksit emisyonu (LCO) olduğu ancak (3) nolu modelden farklı olarak ticaret ve ulaşım altyapısının kalitesini ifade eden (LLPI2) bağımsız değişkeninin kullanıldığı (4) nolu model sonuçlarına göre, ticaret ve ulaşım altyapısının kalitesindeki \%1'lik bir artış karbondioksit emisyonunda \%0.24 oranında bir azalmaya; kişi başına hasıladaki \%1'lik bir artış karbondioksit emisyonunda \%0.10'luk bir artışa; yenilenebilir enerji kaynaklarının kullanım oranındaki \%1'lik bir artış ise karbondioksit emisyonunda \%0.22'lik azalmaya sebebiyet vermektedir.

Tablo 2: Lojistik Faaliyetlerin Karbondioksit Emisyonu Üzerine Etkisi (Bağımlı Değişken: LCO)

\begin{tabular}{|c|c|c|}
\hline Değişkenler - Modeller & (3) & (4) \\
\hline \multirow[t]{2}{*}{ LLPI1 } & -0.357 & \\
\hline & $(0.007)^{*}$ & \\
\hline \multirow[t]{2}{*}{ LLPI2 } & & -0.236 \\
\hline & & $(0.014)^{* * *}$ \\
\hline \multirow[t]{2}{*}{ LGDPPC } & 0.083 & 0.104 \\
\hline & $(0.018)^{* *}$ & $(0.007)^{*}$ \\
\hline \multirow[t]{2}{*}{ LRNC } & -0.221 & -0.224 \\
\hline & $(0.009)^{*}$ & $(0.007)^{*}$ \\
\hline \multirow[t]{2}{*}{ Sabit Parametre } & 11.279 & 10.911 \\
\hline & $(0.000)^{*}$ & $(0.000)^{*}$ \\
\hline Gözlem Sayıs1 & 243 & 243 \\
\hline Birim Say1sı & 27 & 27 \\
\hline $\mathrm{R}^{2}$ & 0.34 & 0.34 \\
\hline \multirow[t]{2}{*}{ F testi $\left(\mathrm{H}_{0}: \mu_{\mathrm{i}} \neq 0\right)$} & 2898.87 & 2846.01 \\
\hline & $(0.000)$ & $(0.000)$ \\
\hline$F$ testi $\left(\mathrm{H}_{0}: \beta_{\mathrm{i}}=0\right)$ & 37.85 & 36.97 \\
\hline \multirow[t]{2}{*}{ Breusch-Pagan LM (Pr>Chi2) } & 479.69 & 446.68 \\
\hline & $(0.000)$ & $(0.000)$ \\
\hline \multirow[t]{2}{*}{ Hausman (Pr>Chi2) } & 38.62 & 42.90 \\
\hline & $(0.000)$ & $(0.000)$ \\
\hline
\end{tabular}




\begin{tabular}{|l|c|c|}
\hline DW & 0.749 & 0.756 \\
\hline Baltagi Wu & 1.137 & 1.152 \\
\hline Pesaran testi & 11.806 & 11.515 \\
& $(0.000)$ & $(0.000)$ \\
\hline \multirow{2}{*}{ Değiştirilmiş Wald testi } & 954.22 & 1646.95 \\
\cline { 2 - 3 } & $(0.000)$ & $(0.000)$ \\
\cline { 2 - 3 } & \multicolumn{2}{|c|}{$(* *$ sirasıyla \%1 ve \%5 düzeyinde anlamlilik seviyelerini göstermektedir. } \\
\hline
\end{tabular}

\section{Sonuç ve Değerlendirme}

Lojistik sektörü, küreselleşmeyle birlikte dünya ticaretinin en önemli halkalarından biri haline gelmiştir. Dünya ticaretinden daha fazla pay almak ve dolayısıyla rekabet gücünü artırabilmek amacıyla ülkelerin lojistik alt yapılarını geliştirmesi elzem bir hal almıştır. Söz konusu süreçte, ülke ekonomilerine katkıda bulunmanın yanında, sürdürülebilirliğin sağlanması açısından çevre ve doğal kaynakların korunması da önem arz etmektedir. Çeşitli uluslararası entegrasyonlar ve örgütler çerçevesinde geliştirilen projeler, alınan kararlar, uygulanan politikalar ve stratejiler sürdürülebilirliğin ve dolayısıyla çevre ve doğal kaynakların korunması gerektiğinin önemini ortaya koymaktadır. Sürdürülebilir kalkınma kapsamında yeni bir ekonomi modeli olarak adlandırabileceğimiz yeşil ekonomi, çevre ve doğal kaynaklar ile ekonomik gelişme arasında denge kuran, koruyarak büyümenin sağlanmasına imkan veren bir politika olarak ortaya çıkmıştır.

Yeşil ekonomi birçok kavramı beraberinde getirmiş ve ekonomi literatürüne kazandırmıştır. Bu kavramlardan biri de yeşil lojistik olmuştur. Lojistik faaliyetlerin en önemli unsurlarından biri olan taşımacılık, taşıma araçlarında kullanılan fosil yakıtlar nedeniyle sera gazı emisyonunu artırmaktadır. Bu durum çevre ve hava kirliliğini ve dolayısıyla atmosferdeki sera gazı oranının artmasına sebep olmaktadır. Yeşil lojistik kapsamında lojistik faaliyetlerin çevreyi, doğayı ve doğal kaynakları koruyacak bir şekilde koordine edilmesi amaçlanmaktadır.

Avrupa Birliği üyesi 26 ülke ile Türkiye'nin lojistik performans endeksleri ile sera gazı ve karbondioksit emisyonları arasındaki ilişkinin ele alındığı çalışmada, endekslerdeki artış ile sera gazı ve karbondioksit emisyonları arasında negatif ve anlamlı bir ilişki tespit edilmiştir. Lojistik performans endekslerindeki artış sera gazı ve karbondioksit emisyonu üzerinde azaltıcı bir etkiye neden olmaktadır. Ayrıca, kurulan her bir model sonuçlarına göre yenilenebilir enerji kaynaklarının kullanımındaki artışlar her iki emisyon türü üzerinde de azaltıcı etki yapmaktadır. Buna karşılık kişi başına hasıla ile her iki emisyon türü arasındaki ilişki pozitif yönlü ve anlamlıdır. Analiz sonuçları değerlendirildiğinde literatürde yer alan çalışmalarla özellikle lojistik faaliyetlerdeki gelişmenin sera gazı emisyonları üzerinde azaltıcı etki yapması noktasında örtüştüğü görülmektedir. Çalışmada AB26 ülkelerinin ele alınma nedeni olan Avrupa 2020 


\section{Emrullah METE}

Sürdürülebilir Kalkınma Kapsamında Yeșil Lojistik: Avrupa Birliği ve Türkiye Örneği

Stratejisi kapsamında yer alan sera gazı emisyonlarını azaltma hedefinin gerçekleşmesine lojistik faaliyetlerdeki gelişmelerle katkı sağlanabilmektedir. Politika yapıcıların çevre ve hava kirliliğini azaltma noktasında çeşitli stratejiler geliştirerek uygulamaya koyması sağlıklı yaşamın ve doğal kaynakların korunması noktasında önem arz etmektedir. Bu kapsamda, özellikle taşımacılık alanında fosil yakıt tüketimini ve sera gazı emisyonunu azaltan taşıma araçlarının kullanılması, mümkün olduğunca taşıma mesafelerinin azaltılması gibi hususlar dikkate alınmalıdır. Ayrıca, fosil yakıt kullanan araçlar yerine yenilenebilir enerji kaynaklarının kullanımına imkan veren araçların kullanılması ve/veya üretilmesi, ticaret ve ulaşım altyapısı için yapılan yatırımlarda yeşil kavramının mutlak surette dikkate alınması da önem arz etmektedir. Ülkelerin coğrafi konumları da dikkate alınarak deniz, hava ve kara taşımacılığı noktasında düşük emisyonun hedeflendiği alt yapı yatırımlarının gerçekleştirilmesi politika yapıcılar açısından önemli bir husustur. 


\section{Kaynakça}

Aldakhil, A.M., Nassani, A.A., Awan, U., Abro, M.M.Q ve Zaman, K. (2018), Determinants of Green Logistics in BRICS Countries: An Integrated Supply Chain Model for Green Business, Journal of Cleaner Production, 195, 861-868.

Breusch, T.S. ve Pagan, A.R. (1980). The Lagrange Multiplier Test and Its Applications to Modelspecification Tests in Econometrics, Review of Economic Studies, 47(1), 239-53.

Cui, Q. ve Li, Y. (2015), An Empirical Study on the Influencing Factors of Transportation Carbon Efficiency: Evidences From Fifteen Countries, Applied Energy, 141, 209-217.

Dereli, M. ve Aytaç, A. (2019), Uluslararası Ticaret ve Çevre İlişkisi Kapsamında Yeşil Lojistik Kavramı: Avrupa Birliği ve Türkiye, Sosyal ve Beşeri Bilimlere Multidisipliner Bakış, 41, 68-100.

Driscoll, J.C. ve Kraay, A.C. (1998). Consistent Covariance Matrix Estimation with Spatially Dependant Panel Data, Review of Economics and Statistic, 80(4), 549-560.

Khan, S.A.R. (2019), The Effect of Green Logistics on Economic growth, Social and Environmental Sustainability: An Empirical Study of Developing Countries in Asia, Preprints, 2019010104 (doi: 10.20944/preprints201901.0104.v1).

Khan, S.A.R., Zhang, Y. ve Nathaniel S. (2020), Green Supply Chain Performance and Environmental Sustainablity: A Panel Study, LogForum, 16(1),141-159.

Lai, K.H. ve Wong, C.W., (2012), Green Logistics Management and Performance: Some Empirical Evidence From Chinese Manufacturing Exporters, Omega, 40, 267-282.

Mariano, E. B., Gobbo Jr, J. A., De Castro Camioto, F. ve Nascimento Rebelatto, D. A., (2017). $\mathrm{CO}_{2}$ Emissions and Logistics Performance: A Composite Index Proposal, Journal of Cleaner Production, 163, 166-178.

Nakamichi K., Hanaoka S. ve Kawahara Y. (2016), Estimation of Cost and $\mathrm{CO}_{2}$ Emissions with a Sustainable Cross-Border Supply Chain in The Automobile Industry: A Case Study of Thailand and Neighboring Countries, Transportation Research Part D: Transport and Environment, 43, 158-168.

Öncü, E. ve Özdemir, Ö., (2020), Ekonomik Büyüme ve Ulaştırma Altyapı Kalitesinin $\mathrm{CO}_{2}$ Emisyonuna Etkisinin İncelenmesi, Nişantaşı Üniversitesi Sosyal Bilimler Dergisi, 8, 4554.

Pesaran, M.H. (2004). General Diagnostic Tests for Cross Section Dependence in Panels, Cambridge Working Papers in Economics, No: 435.

T.C. Dışişleri Bakanlığı, Avrupa Birliği Başkanlığı, Sektörel Politikalar Daire Başkanlığı (2020). Fasıl 27: Çevre ve İklim Değişikliği, Avrupa Birliği'nin Çevre ve İklim Değişikliği Politikası, Erişim Adresi: https://www.ab.gov.tr/fasil-27-cevre 92.html (22.11.2020) 


\section{Emrullah METE}

Sürdürülebilir Kalkınma Kapsamında Yeșil Lojistik: Avrupa Birliği ve Türkiye Örneği

T.C. Kalkınma Bakanlığı Onuncu Kalkınma Planı Özel İhtisas Komisyonu Raporu (2014), Lojistik Hizmetlerin Geliştirilmesi (Yayın No: KB: 2884- ÖİK: 729). http://www.sbb.gov.tr/wp-

content/uploads/2018/10/10_LojistikHizmetlerininGelistirilmesi.pdf (22.11.2020)

Takım, A. (2015). Uluslararası Ticarete Giriş Kavram, Teori, Politika ve Uygulama, Bursa: Ekin Yayınevi.

Tatoğlu, F.Y. (2013), Panel Veri Ekonometrisi Stata Uygulamalı, İstanbul: Beta Yayınevi.

Wang, D.F., Dong, Q-L., Peng, Z-M., Khan, S.A.R., ve Tarasov, A. (2018) The Green Logistics Impact on International Trade: Evidence from Developed and Developing Countries Sustainability, 10, 1-19.

Yılmaz, G.A. ve Yı1dırır Keser, H. (2018), Uluslararası Taşımacılık Sektörünün Etkinliğinde Yeşil Lojistik, IV. Uluslararası Kafkasya-Orta Asya Dış Ticaret ve Lojistik Kongresi Didim/Aydin 2018, 638-646. http://ulk.ist/media/kitap/IV-UKODTLK/uluslararasitasimacilik-sektorunun-etkinliginde-yesil-lojistik.pdf (22.11.2020)

Yu, Z., Golpira, H. ve Khan, S.A.R. (2018), The Relationship between Green Supply Chain Performance, Energy Demand, Economic Growth and Environmental Sustainability: An Empirical Evidence from Developed Countries, LogForum, 14 (4), 479-494. 